\title{
Upgrading of recycled polypropylene by preparing flame retarded layered composite
}

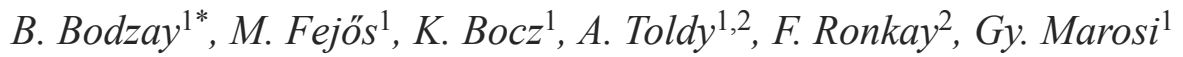 \\ ${ }^{1}$ Budapest University of Technology and Economics, Faculty of Chemical Technology and Biotechnology, Department of \\ Organic Chemistry and Technology, Budafoki út 8., H-1111 Budapest, Hungary \\ ${ }^{2}$ Budapest University of Technology and Economics, Faculty of Mechanical Engineering, Department of Polymer \\ Engineering, Müegyetem rkp. 3., H-1111 Budapest, Hungary
}

Received 26 January 2012; accepted in revised form 6 June 2012

\begin{abstract}
Upgrading of polypropylene waste was performed by different composite technologies, in order to improve the flame retardancy combined with preserved or improved mechanical properties. The polymer waste of density below $900 \mathrm{~kg} / \mathrm{m}^{3}$ is originated from end-of-life vehicles (ELV) after comminution, density separation and comprehensive analysis. Intumescent flame retardant system was used for reducing the flammability; while chopped glass fibre reinforcement was used to compensate the deterioration of mechanical properties caused by flame retardant additives. In mixed composite beside of flame retardants, the reinforcement effect of glass fibre can not be realized; therefore with modification of composite structure (but maintaining the composition) a multilayer composite was developed, which contains $65.5 \%$ of recycled polymer, where the core is reinforced with glass fibre covered by flame retarded shell layers. Enhanced flame retardancy ( 4 min longer time to escape) was achieved by using this layered composite compared to the mixed composite, thus the time to escape could be extended only with modification of composite structure.
\end{abstract}

Keywords: polymer composites, recycling, multilayer structure, flame retardant, glass fibre reinforced

\section{Introduction}

According to a recent market analysis the application of recycled polymers in the automotive industry is still not usual because of their poor properties [1]. Although the acceptable upper limit for the application of secondary plastics in combination with primary raw materials changes in a wide range (20-100\%), the use of secondary plastic materials is still lower than required by the European legislation (COM/2001/0031, 99/31/EC, 2000/53/EC, 2002/96/ EC, 2003/108/EC) aiming at fostering the development of environmental-friendly technologies with reduction of waste [2].

Secondary plastics have low market value because of their uneven composition and purity; however, their value can be increased by separation in order to obtain relatively homogeneous fractions upgraded with reinforcement, functionalization, restabilization and flame retardancy [3, 4].

In the field of transportation both mechanical and flame retardant properties play important role in the material development [5]. The application of flame retardant additives usually considerably deteriorates the mechanical properties [6-10]. In order to fulfil these antagonistic requirements polymer composites of layered (or sandwich) structure can be a solution.

Concerning the flame retardancy of layered composite structures, it should be noted, that the nonhomogeneous nature of the core composite materi-

\footnotetext{
${ }^{*}$ Corresponding author, e-mail: bbodzay@mail.bme.hu

(c) BME-PT
} 
als may cause problems, especially if the adhesion between the layers is not adequate. Delamination of the skin, uneven melting of the core and skin, and edge effects are the factors that must be taken into consideration evaluating the flame retardancy results. Using usual bench-scale test methods such as the Cone Calorimeter test the core composites may not react as a solid homogeneous material would be expected to [11]. If halogen-free solution is required the flammability of polypropylene (PP) is mostly reduced by application of intumescent additives $[12,13]$. Application of intumescent flame retardant additives is favourable because of their low toxicity, action in solid state and suppressed smoke evolution in case of fire [14]. Considering the enhancement of mechanical properties of the composites, fibre-reinforcement offers a cost-effective solution. Besides providing high strength, stiffness and impact properties, the inorganic fibres possess other advantages, such as inflammability, therefore they are widely utilized in thermosets and thermoplastics [15]. The environmentally and ecologically harmless glass fibres are often used as reinforcement also in flame retarded composites [16]. The application of polymer waste as matrix of composites is both ecologic and economic solution providing driving force to reuse the plastic waste in a competitive form. Matko and his co-workers [9] have developed a method for rendering pure polypropylene flame retardant with additives consisting of mainly recycled materials, which reduce considerably the material costs. Strongly reduced heat release rate and high flame retardancy classification was achieved with application of recycled ground tires, and recycled polyurethane in PP, at the expense of the deteriorated mechanical properties. Therefore the aim of this study was to find a costeffective and environmentally friendly way for producing useful materials of higher value from polymer waste by improving the flame retardancy combined with preserved or improved mechanical properties. In the present approach composites containing glass fibre reinforced recycled polypropylene core covered with flame retarded secondary polymer layers were designed. Whilst most of the papers dealing with polymer waste perform only model experiments using mixtures of pure polymers, in this work real industrial car shredder, obtained from end-oflife cars, was used as secondary raw material.

\section{Materials and methods}

\subsection{Materials}

The recycled polypropylene (ASR $\rho<900 \mathrm{~kg} / \mathrm{m}^{3}$ ) supplied by Alcufer Ltd., (Fehérvárcsúrgó, Hungary) separated to density fractions, originated from light fraction of automobile shredder residue (ASR) obtained from shredding of end-of-life vehicles (ELV). After a comprehensive component analysis (Fourier transform infrared spectroscopy - FTIR, Raman, thermogravimetry - TG, differential scanning calorimetry - DSC) [17], it was found that below the density of $900 \mathrm{~kg} / \mathrm{m}^{3}$ the main polymer component is polypropylene ( $>78 \%$ ), melt flow rate (MFR) $\left(190^{\circ} \mathrm{C}, 2.16 \mathrm{~kg}\right) 2.14 \mathrm{~g} / 10 \mathrm{~min}$ and its inorganic filler residue content (determined by heating under mass loss calorimeter with heating wire of $900^{\circ} \mathrm{C}$, which means approx. $650^{\circ} \mathrm{C}$ on the surface of the samples) is lower than 0.75 mass $\%$, containing mainly talc, calcium-carbonate and short glass fibre. As some of the inorganic fillers undergo decomposition at this temperature the inorganic filler content is somewhat higher than the determined residue.

As reinforcing material in the core of the layered structure and in the mixed polyolefin composite chopped glass fibre (GF) (DS 2200-13P) 3B - Fibreglass Company (Battice, Belgium) (Table 1) was used.

The contained intumescent flame retardant (IFR), applied in the flame retarded shell, consisted of ammonium polyphosphate (APP) (Exolit AP 422) Clariant GmbH. (Kornkamp, Germany), recycled polyurethane (RecPUR) Amatech-Polycel Inc. (Erie, Pennsylvania, USA), glyceryl-monostearate (GMS) (Estol) Chemiplast Ltd. (Budapest, Hungary) and ethylene-vinyl-acetate (EVA) (Ibucell K100), H.B. Fuller (St Paul, MN, USA). This intumescent flame retardant system was successfully applied in polyolefin matrix in our previous work [9]. The APP is the phosphorous containing flame retardant additive which forms intumescent char with application of recycled PUR as a carbon source. GMS was used as a compatibilizer and EVA to improve the flexibility.

Table 1. Properties of the DS 2200-13P type glass fibre

\begin{tabular}{|l|c|c|}
\hline \multicolumn{1}{|c|}{ Property } & Unit & E-glass \\
\hline Fibre length & $\mathrm{mm}$ & 4 \\
\hline Diameter & $\mu \mathrm{m}$ & 13 \\
\hline Moisture content & $\%$ & $\max .0 .05$ \\
\hline Solid content & $\%$ & 0.5 \\
\hline
\end{tabular}




\subsection{Preparation of samples}

Compounding: the components were homogenized in a Brabender Plasti Corder (PL 2000) Brabender GmbH \& Co. KG (Duisburg, Germany) equipped by a $50 \mathrm{~cm}^{3}$ kneader chamber, at $190^{\circ} \mathrm{C}$, with a rotor speed of $50 \mathrm{rpm}$, for $10 \mathrm{~min}$.

Compression moulding of the test sheets: the compounds were compressed in a Collin P 200 E Dr. Collin GmbH (Ebersberg, Germany) laboratory compression moulding machine at $190^{\circ} \mathrm{C}$, with $10 \mathrm{bar}$, for $10 \mathrm{~min}$, the layered composites were prepared at $180^{\circ} \mathrm{C}, 50$ bar for $10 \mathrm{~min}$. The sample thickness was $4 \mathrm{~mm}$.

\subsection{Evaluation methods}

Comparative mechanical tests were carried out by ZWICK Z020 universal tester Zwick GmbH \& Co. KG (Ulm, Germany). The tensile test speed was $10 \mathrm{~mm} / \mathrm{min}$ with clamping distance of $80 \mathrm{~mm}$ using rectangular strip specimens with cross-section of $4 \mathrm{~mm} \times 10 \mathrm{~mm}$. Tensile strength and tensile modulus were calculated from the force-displacement curves obtained from the tensile test. The threepoint bending measurements were also carried out using Zwick Z020 device at $64 \mathrm{~mm}$ gauge length and $5 \mathrm{~mm} / \mathrm{min}$ crosshead speed, following the ISO178 standard. The tests were carried out at room temperature and average values were calculated from the results of five test specimens. SEM pictures were taken of the composites by JSM 6380LA type JEOL (Tokyo) Scanning Electron Microscope. The flame retardant performance was characterized by limiting oxygen index (LOI) according to the standard ASTM D 2863 and UL-94 (ASTM D 635, ASTM D 3801) flammability measurements. While limiting oxygen index gives information about ignitability in controlled atmosphere, UL-94 classification (HB-worst, V2, V1, V0-best) is used for determination of dripping and fire spreading rate. For investigation of surface flammability UL 94 5VA\&5VB (ASTM D 5048) was used, which dis- tinguishes 5VA (non-burning), and 5VB (throughburning) materials.

The Mass Loss type Cone Calorimeter tests were carried out by the device of Fire Testing Technology Inc. (East Grinstead, England) instrument, following the procedures in ASTM E 906 standard method for measuring heat release of materials during their burning. The results of 3 measurements were averaged. Square specimens $(100 \mathrm{~mm} \times 100 \mathrm{~mm} \times$ $4 \mathrm{~mm}$ ) were irradiated at a heat flux of $50 \mathrm{~kW} / \mathrm{m}^{2}$. This method is based on the principle of direct measurement of the convective and radiant heat liberated using a mass loss calorimeter fitted with thermopiles. Thermocouples are embedded in the mass loss calorimeters' chimney to measure the temperature of the gases directly. By calibrating them by combustion methane gas at each heat flux, heat release values for each sample can be determined throughout the experiments. It makes also possible to monitor the change of sample mass during the burning process.

\section{Results and discussion}

In order to upgrade the selected polymer waste fraction $\left(<900 \mathrm{~kg} / \mathrm{m}^{3}\right)$, flame retardant additives and reinforcing fibres were introduced into composite materials with two technologies. In case of mixed composite (RMC) the components were homogenized in an internal mixer and hot-pressed to obtain $4 \mathrm{~mm}$ thick homogeneous material, while the other composite had a layered structure (RLC) consisting of a $2 \mathrm{~mm}$ thick reinforced core layer (RC) and two $1 \mathrm{~mm}$ thick flame retarded outer layers (RS) pressed together see in Figure 1.

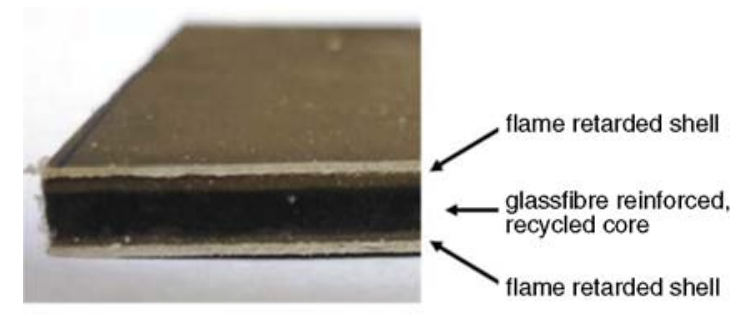

Figure 1. The structure of the layered composite

Table 2. Composition of the shell, core layers and composites

\begin{tabular}{|l|c|c|c|}
\hline \multicolumn{1}{|c|}{ Materials } & $\begin{array}{c}\text { Recycled shell } \\
\text { (RS) }\end{array}$ & $\begin{array}{c}\text { Recycled core } \\
\text { (RC) }\end{array}$ & $\begin{array}{c}\text { Recycled composites } \\
\text { (RMC, RLC) }\end{array}$ \\
\hline Recycled matrix $\left(\mathrm{ASR} \rho<0.9 \mathrm{~g} / \mathrm{cm}^{3}\right)$ & $36 \%$ & $70 \%$ & $53.0 \%$ \\
\hline EVA & $13 \%$ & - & $6.5 \%$ \\
\hline GMS & $1 \%$ & - & $0.5 \%$ \\
\hline APP & $25 \%$ & - & $12.5 \%$ \\
\hline Recycled PUR & $25 \%$ & - & $12.5 \%$ \\
\hline Glass fibre & - & $30 \%$ & $15 . \%$ \\
\hline
\end{tabular}


The layers of the 'sandwich' composite were also investigated separately. The composition of the samples is summarized in Table 2.

The composites having high waste content including the recycled matrix and recycled PUR as an additive (RS: 61\%, RC: 70\%, RMC, RLC: 65.5\%) are advantageous from economical and environmental aspects.

In order to compare the efficiency of the different composite technologies (mixed and layered composites) their flame retardant and mechanical properties of the sandwich composites and their each layer were determined.

\subsection{Flammability}

The LOI and UL-94 results are summarized in Table 3. It can be concluded that the intumescent shell, as expected, reached V-0 UL-94 level of fire retardancy and much higher LOI (28) than the core material (HB and 19 respectively). If the components are simply mixed together the UL-94 classification remained $\mathrm{HB}$, and the LOI values increased only with 2 units (21), which means that it is still very combustible in air. Applying flame retarded layer as an outer shell of layered composite, the UL-94 level remained HB, however, the LOI increased from 19 to 25 . During the UL-94 classification of layered composite structures the cross section of the sample is exposed to fire during the ignition, therefore the core of the layered composites, being the most ignitable layer of the material, determines the achieved classification. Taking into account the possible application areas of this material, it is quite clear that only the outer layers (the surface), will be exposed to fire, the classification of the shell in case of layered composites is more relevant. The UL-94 5VA\&5VB surface flammability test (Table 3) verifies that similarly to the shell, the layered composite reaches also the best (5VA) classification in contrast to the core and mixed composite (5VB) results.
Although the composition of the mixed and layered composites is exactly the same, the application of layered structure causes improvement in the oxygen index from 21 (RMC) in case of mixed composite to 25 (RLC) at layered composites, furthermore significantly (by approx. $80 \%$ ) reduces the burning rate as well.

Concerning the heat release rate (HRR) results shown in Figure 2 the core contains only $70 \%$ PP and $30 \%$ glass fibre which helps the heat diffusion; therefore the pHRR is reduced compared to the RecPP. The $4 \mathrm{~mm}$ thick flame retarded shell causes more than 4 min shift in the time of peak heat release rate owing to the formed intumescent char on the surface of the material. This layer is intact up to $500 \mathrm{~s}$, then it looses its' protecting effect. The intumescent flame retardant system significantly (by 70\%) reduced the peak heat release rate (pHRR) of both mixed and layered composites compared to the matrix materials. However, comparing the two technologies applied for producing the composites, it is clear that the application of layered structure delayed the time to pHRR and also the intensive burning by approx. $200 \mathrm{~s}$. After $200 \mathrm{~s}$ the shell layer lost its protecting effect and the HRR values approached the curves of mixed composites. Con-

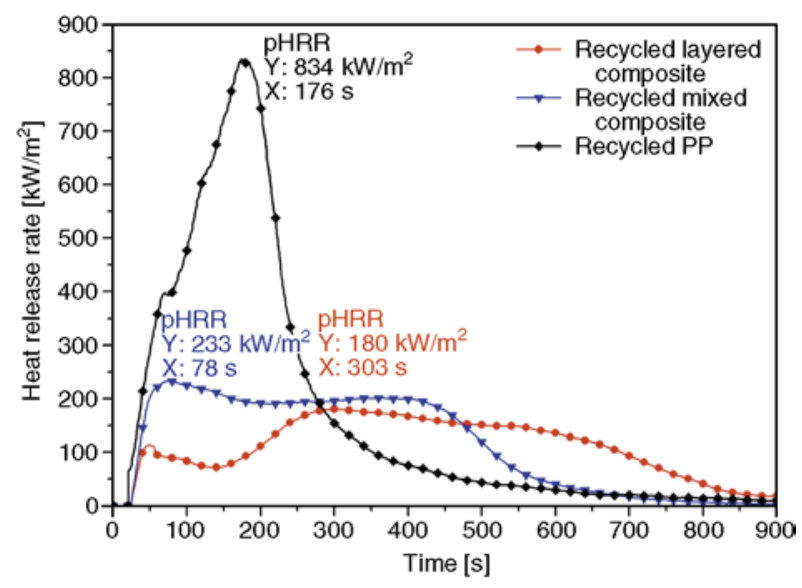

Figure 2. Heat release rate results of the mixed and layered composites

Table 3. LOI and UL-94 ratings

\begin{tabular}{|l|c|c|c|c|}
\hline \multicolumn{1}{|c|}{ Samples } & $\begin{array}{c}\text { LOI } \\
{[\%]}\end{array}$ & UL-94 & $\begin{array}{c}\text { Burning rate } \\
{[\mathbf{m m} / \mathbf{m i n}]}\end{array}$ & $\begin{array}{c}\text { UL-94 } \\
\text { 5VA \& 5VB }\end{array}$ \\
\hline Recycled matrix & 19 & HB & 31.1 & - \\
\hline Recycled core (RC) & 19 & HB & 24.7 & $5 \mathrm{VB}$ \\
\hline Recycled shell (RS) & 28 & $\mathrm{~V}-0$ & - & $5 \mathrm{VA}$ \\
\hline Recycled mixed composite (RMC) & 21 & $\mathrm{HB}$ & 25.5 & $5 \mathrm{VB}$ \\
\hline Recycled layered composite (RLC) & 25 & HB & 3.6 & 5VA \\
\hline
\end{tabular}




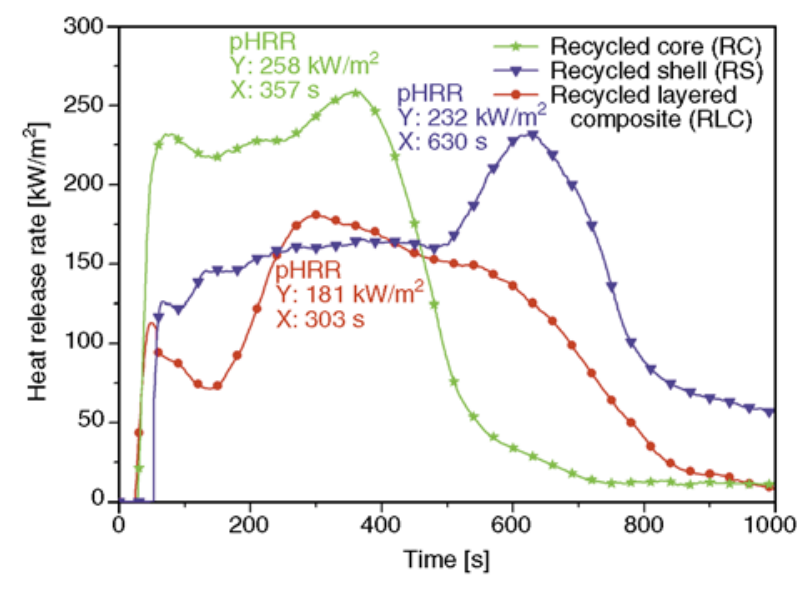

Figure 3. Heat release rate results of the layered (sandwich) composite, core and shell materials

sequently if the whole amount of the FR additives is concentrated into the surface layer both the intensity and the time of pHRR decreases.

In order to understand more details of this behaviour, the layers and the layered composite are compared in Figure 3. Surprisingly the HRR curve of layered structure runs lower at the beginning than that of shell with higher overall FR content and the loss of the protective function occurs earlier than in case of shell tested alone (RS). The difference occurs because the glass fibre in the core of the layered structure, having flame retarded layer of $1 \mathrm{~mm}$ on the surface, helped the heat diffusion under the surface [12]. Thus the pHRR was reduced at the initial phase (until $250 \mathrm{~s}$ ). Later on in case of the $4 \mathrm{~mm}$ thick shell material the accumulated heat leads to decomposition of the surface structure and breakdown of its protecting effect, leading to a second intensive peak of heat release. It does not occur with the layered composite in which the heat is carried away by the heat conductive sublayer, therefore the protecting effect of the intumescent char is similar to the shell material but this protection effect lasts until the end of test. No significant cracks or delamination occurred at the surface of the composite see on
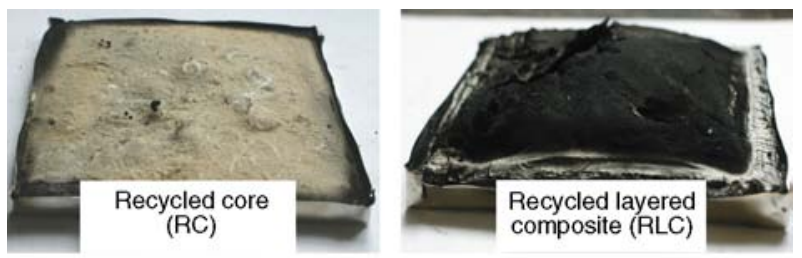
a)

b)

Figure 4. Residues after burning; recycled core (a), recycled layered composite (b)

Figure $4 \mathrm{~b}$ compared to the uncovered residue made of glass fibres of the recycled core (RC) (Figure 4a).

The total heat released (THR) was approximately the same during the burning of both mixed and layered composites (see Table 4), but in case of the layered one, the main heat release step was prolonged by $220 \mathrm{~s}$ (almost 4 minutes) in time compared to the mixed one, due to the protecting effect of the outer flame retarded layers, where the intumescent flame retardants were concentrated. Furthermore the amount of residue after burning was significantly increased in case of RLC (see Table 5). The most surprising result of Table 4 is the lower amount of total heat released of the composites than that of shell material in spite of their less fire retardant content. It can not be explained merely by the presence of $15 \%$ non-combustible glass fibre, consideration of the preserved protecting capability of their surface layer, as described at the explanation of Figure 3, is also required.

Based on the results in Figure 2 and 3 and Table 4 it can be concluded that the layered composite is the more advantageous than the shell (containing dou-

Table 5. The residue of the samples after burning

\begin{tabular}{|l|c|}
\hline \multicolumn{1}{|c|}{ Samples } & Residue \\
\hline Recycled matrix (ASR $\rho<900 \mathrm{~kg} / \mathrm{m}^{3}$ ) & $0.7 \%$ \\
\hline Recycled shell (RS) & $17 \%$ \\
\hline Recycled core (RC) & $30.5 \%$ \\
\hline Recycled mixed composite (RMC) & $13 \%$ \\
\hline Recycled layered composite (RLC) & $16 \%$ \\
\hline
\end{tabular}

Table 4. Numeric results of mass loss calorimeter tests

\begin{tabular}{|l|c|c|c|}
\hline \multicolumn{1}{|c|}{ Samples } & $\begin{array}{c}\text { Time of peak heat release rate }^{\mathbf{a}} \\
{[\mathbf{s}]}\end{array}$ & $\begin{array}{c}\text { Peak heat release rate (pHRR) } \\
{\left[\mathbf{k W} / \mathbf{m}^{\mathbf{2}}\right]}\end{array}$ & $\begin{array}{c}\text { Total heat released (THR) }^{\mathbf{c}} \\
{\left[\mathbf{M J} / \mathbf{m}^{\mathbf{2}}\right]}\end{array}$ \\
\hline Recycled matrix & 176 & 834 & 155 \\
\hline Recycled core (RC) & 357 & 258 & 112 \\
\hline Recycled shell (RS) & 630 & 232 & 136 \\
\hline Recycled mixed composite (RMC) & 78 & 233 & 102 \\
\hline Recycled layered composite (RLC) & 303 & 181 & 100 \\
\hline
\end{tabular}

adeviation of method $\pm 5 \mathrm{~s}$

${ }^{b}$ deviation of method $\pm 39 \mathrm{~kW} / \mathrm{m}^{2}$

${ }^{c}$ deviation of method $\pm 3 \mathrm{MJ} / \mathrm{m}^{2}$ 
ble amount of flame retardant), because of the decrease in the peak HRR, the shift of its position by approx. $200 \mathrm{~s}$ and the significantly reduced THR. The combined application of FR shell and reinforced core of enhanced heat conductivity layers in the form of layered composites resulted in a synergistic effect, both in terms of total heat released and peak of HRR.

\subsection{Mechanical properties}

The main mechanical properties of the samples were evaluated by tensile and flexural tests in order to trace the changes caused by different additives.

In comparison to the matrix (RecPP), the tensile strength of the flame retardant containing shell (RS) was reduced by $50 \%$ (Figure 5a). Applying glass fibre reinforcement the tensile strength of the core (RC) could be increased by $25 \%$ compared to the matrix. The reinforcement effect of the same amount of glass fibre in the mixed composite (RMC was not enough to balance the negative effect of flame retardant system, thus the tensile strength shows slight $(14.7 \mathrm{MPa})$ decrease compared to the matrix
(16.1 MPa). In case of layered structure better compensation can be achieved, therefore this structure is considered more favourable than the mixed one in terms of tensile strength.

The tensile moduli of the materials are shown in Figure $5 \mathrm{~b}$. While the presence of the flame retardant additives slightly diminishes the stiffness, the reinforcement with glass fibre raises it significantly. The tensile moduli of all composite samples prepared either by mixing (RMC) or by layering technology (RLC) are approximately similar to that of core material (RC): 1.2 GPa. It is surprising because the glass fibre content in these composites is less than in the core material. It seems that the FR components and the macromolecules adsorbed in their interlayers compensate the lower content of the reinforcing fibres in this respect.

Figures $6 \mathrm{a}$ and $6 \mathrm{~b}$ summarize the results of the flexural tests. Similarly to the mechanical properties showed previously, the flexural strength and modulus of the flame retardant containing samples decreased, but the glass fibre significantly improved them.
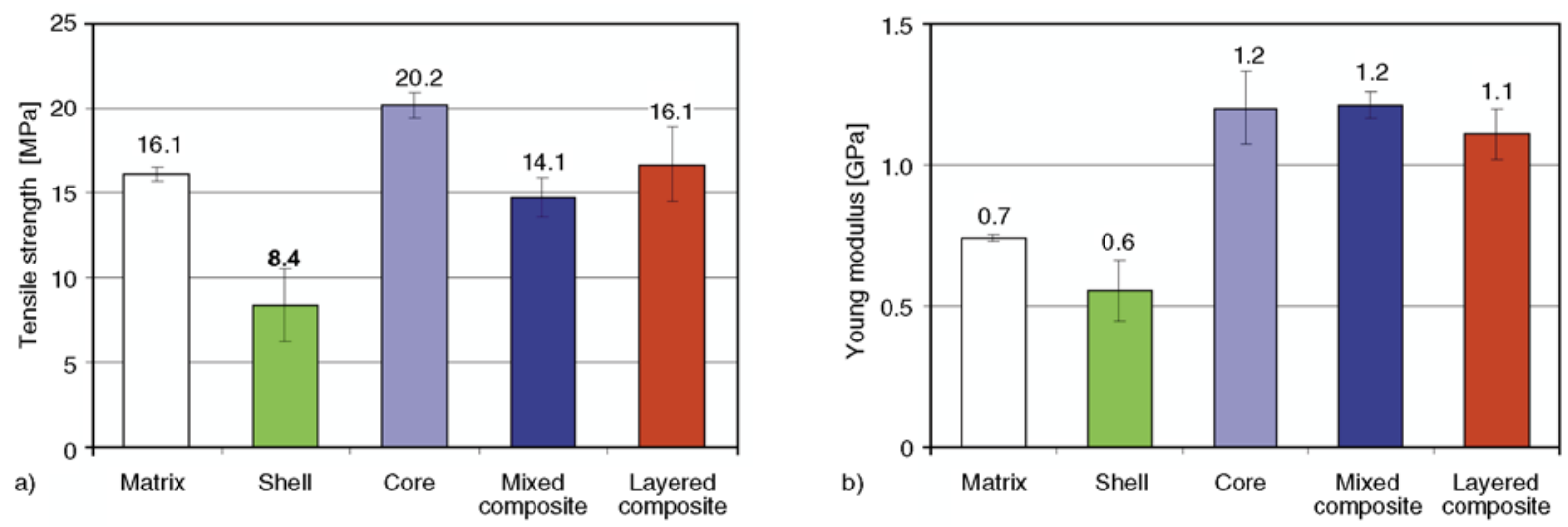

Figure 5. Tensile strength (a) and modulus (b) of the recycled samples
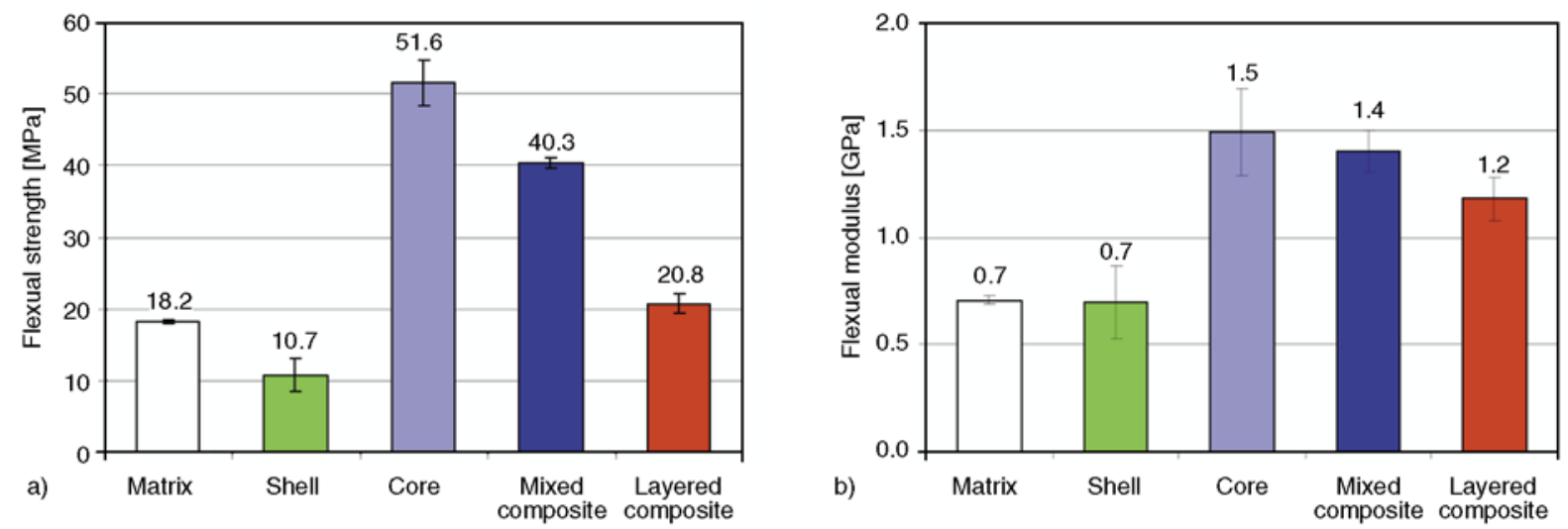

Figure 6. Flexural strength (a) and modulus (b) of the recycled samples 


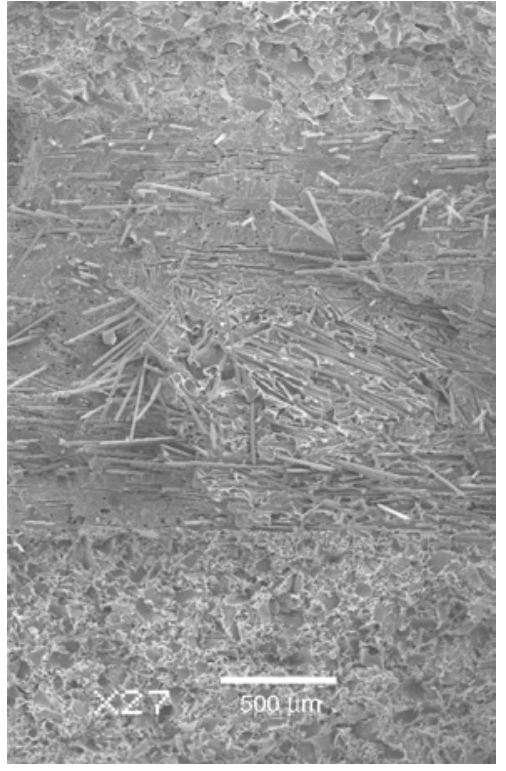

Figure 7. SEM picture of layered composite

As it was expected, the results of the mixed composite (RMC) are between the core (RC) and shell (RS) or reference matrix, but the flexural properties of the layered composites (RLC) are somewhat worse than those of the mixed composites, because the reinforcement is concentrated in the middle layer of the composite, which can admit higher flexibility, but attains the flexural strength of the matrix. Application of this recycled layered structure as an internal element of cars, such as dashboard it has to be flexible, because of the slight deformation of each car element, therefore EVA was used for this purpose. In this point of view, the layer composite shows better moduli than the mixed one. Nevertheless, it can be stated, that besides improved fire retardancy also the tensile and flexural properties of the layered composites reach the mechanical properties of the reference matrix.

Based on the SEM picture (Figure 7) it can be stated, that the orientation of the fibres is not considerable, it can be observed only near the surface of the core (interlayer). It is assumed that the compression moulding process did not induce any fibre orientation effects which might influence the mechanical properties.

\section{Conclusions}

The aim of this work was to find a cost-effective, environmentally friendly way for upcycling of polypropylene waste in order to produce useful materials of higher value. Different composite tech- nologies were used to improve the flame retardancy besides constant or improved mechanical properties using recycled polypropylene and layered structure. Chopped glass fibre was used as reinforcing agent in recycled polypropylene waste separated from automotive shredder residue (ASR), with density below $900 \mathrm{~kg} / \mathrm{m}^{3}$, and intumescent flame retardant system served for the reduction of flammability with application of recycled polyurethane as a charring agent. Layered structure was used in order to eliminate the deterioration of mechanical properties caused by flame retardant additives. The application of the flame retarded shell material decreased the peak of HRR of the sandwich composites by approx. $80 \%$ in comparison to recycled PP matrix and increased the LOI from 19 of the core material to 24. The mechanical properties of the flame retarded recycled layered composite reached the properties of the reference polypropylene, therefore the composites containing recycled materials are still proper for certain engineering applications.

\section{Acknowledgements}

The recycling of polymer waste was promoted by an EU7 framework with the title of 'Magnetic sorting and ultrasound sensor technologies for production of high purity secondary polyolefins from waste' (W2PLASTICS, No. 212782), and by Recytech project (TECH_08_A4/2-2008142) called 'Elaboration of Recycling Technologies for non-metallic automotive and electronic waste avoiding further deposition of organic materials subsidized by the National Development Agency (NFÜ)'. The publishing of this paper was supported by the Hungarian Scientific Research Fund (OTKA PD 72722), the János Bolyai Scholarship of the Hungarian Academy of Science and the ERA Chemistry (code NN 82426). This work is connected to the scientific program of the 'Development of quality-oriented and harmonized R+D+I strategy and functional model at BME'. This project is supported by the New Hungary Development Plan (Project ID: TÁMOP-4.2.1/B-09/1/KMR-2010-0002). The work reported in this paper has been developed in the framework of the project 'Talent care and cultivation in the scientific workshops of BME' project. This project is supported by the grant TÁMOP-4.2.2.B-10/1-2010-0009.

\section{References}

[1] Toldy A., Bodzay B., Tierean M.: Recycling of mixed polyolefin wastes. Environmental Engineering and Management Journal, 8, 967-971 (2009).

[2] Bellmann K., Khare A.: European response to issues in recycling car plastics. Technovation, 19, 721-734 (1999).

DOI: $10.1016 / \mathrm{S} 0166-4972(99) 00081-4$ 
[3] Bocz K., Toldy A., Kmetty Á., Bárány T., Igricz T., Marosi Gy.: Development of flame retarded self-reinforced composites from automotive shredder plastic waste. Polymer Degradation and Stability, 97, 221227 (2012).

DOI: $10.1016 /$ j.polymdegradstab.2011.12.029

[4] Fávaro S. L., Ganzerli T. A., de Carvalho Neto A. G. V., da Silva O. R. R. F., Radovanovic E.: Chemical, morphological and mechanical analysis of sisal fiberreinforced recycled high-density polyethylene composites. Express Polymer Letters, 4, 465-473 (2010). DOI: $10.3144 /$ expresspolymlett.2010.59

[5] Marsh G.: Fire-safe composites for mass transit vehicles. Reinforced Plastics, 46, 26-30 (2002).

DOI: $10.1016 / \mathrm{S} 0034-3617(02) 80157-6$

[6] Nachtigall S. M. B., Miotto M., Schneider E., Mauler R. S., Forte M. M. C.: Macromolecular coupling agents for flame retardant materials. European Polymer Journal, 42, 990-999 (2006).

DOI: $10.1016 /$ j.eurpolymj.2005.10.017

[7] Chiu S-H., Wang W-K.: Dynamic flame retardancy of polypropylene filled with ammonium polyphosphate, pentaerythritol and melamine additives. Polymer, 39 1951-1955 (1998).

DOI: 10.1016/S0032-3861(97)00492-8

[8] Almeras X., Le Bras M., Hornsby P., Bourbigot S., Marosi Gy., Keszei S., Poutch F.: Effect of fillers on the fire retardancy of intumescent polypropylene compounds. Polymer Degradation and Stability, 82, 325331 (2003).

DOI: 10.1016/S0141-3910(03)00187-3

[9] Matkó Sz., Répási I., Szabó A., Bodzay B., Anna P., Marosi Gy.: Fire retardancy and environmental assessment of rubbery blends of recycled polymers. Express Polymer Letters, 2, 126-132 (2008). DOI: $10.3144 /$ expresspolymlett.2008.17
[10] Huang N. H., Chen Z. J., Wang J. Q., Wei P.: Synergistic effects of sepiolite on intumescent flame retardant polypropylene. Express Polymer Letters, 4, 743-752 (2010).

DOI: $10.3144 /$ expresspolymlett.2010.90

[11] Grenier A. T., Dembsey N. A., Barnett J. R.: Fire characteristics of cored composite materials for marine use. Fire Safety Journal, 30, 137-159 (1998). DOI: 10.1016/S0379-7112(97)00059-3

[12] Liu Y., Deng C-L., Zhao J., Wang J-S., Chen L., Wang Y-Z.: An efficiently halogen-free flame-retardant longglass-fiber-reinforced polypropylene system. Polymer Degradation and Stability, 96, 363-370 (2011). DOI: $10.1016 /$ j.polymdegradstab.2010.02.033

[13] Zhang S., Horrocks A. R.: A review of flame retardant polypropylene fibres. Progress in Polymer Science, 28, 1517-1538 (2003).

DOI: 10.1016/j.progpolymsci.2003.09.001

[14] Horacek H., Grabner R.: Advantages of flame retardants based on nitrogen compounds. Polymer Degradation and Stability, 54, 205-215 (1996).

DOI: 10.1016/S0141-3910(96)00045-6

[15] Kumar K. S., Ghosh A. K., Bhatnagar N.: Mechanical properties of injection molded long fiber polypropylene composites, Part 1: Tensile and flexural properties. Polymer Composites, 28, 259-266 (2007).

DOI: $10.1002 / p c .20298$

[16] Pozzi P., Taurino R., Zanasi T., Andreola F., Barbieri L., Lancellotti I.: New polypropylene/glass composites: Effect of glass fibers from cathode ray tubes on thermal and mechanical properties. Composites Part A: Applied Science and Manufacturing, 41, 435-440 (2010).

DOI: $10.1016 /$ j.compositesa.2009.12.001

[17] Vajna B., Bodzay B., Toldy A., Farkas I., Igricz T., Marosi Gy.: Analysis of car shredder polymer waste with Raman mapping and chemometrics. Express Polymer Letters, 6, 107-119 (2012).

DOI: 10.3144 /expresspolymlett.2012.12 